\title{
Contralateral Ear Occlusion for Improving the Reliability of Otoacoustic Emission Screening Tests
}

\author{
Emily Papsin, ${ }^{1}$ Adrienne L. Harrison, ${ }^{1}$ Mattia Carraro, ${ }^{1,2}$ and Robert V. Harrison ${ }^{1,2,3}$ \\ ${ }^{1}$ Auditory Science Laboratory, Neuroscience and Mental Health Program, The Hospital for Sick Children, 555 University Avenue, \\ Toronto, ON, Canada M5G 1 X8 \\ ${ }^{2}$ Institute of Biomaterials and Biomedical Engineering, University of Toronto, Toronto, ON, Canada M5S 1A1 \\ ${ }^{3}$ Department of Otolaryngology-Head and Neck Surgery, University of Toronto, 190 Elizabeth Street, Toronto, ON, Canada M5G 2N2
}

Correspondence should be addressed to Robert V. Harrison; rvh@sickkids.ca

Received 10 October 2013; Accepted 28 November 2013; Published 12 January 2014

Academic Editor: Charles Monroe Myer

Copyright (C) 2014 Emily Papsin et al. This is an open access article distributed under the Creative Commons Attribution License, which permits unrestricted use, distribution, and reproduction in any medium, provided the original work is properly cited.

\begin{abstract}
Newborn hearing screening is an established healthcare standard in many countries and testing is feasible using otoacoustic emission (OAE) recording. It is well documented that OAEs can be suppressed by acoustic stimulation of the ear contralateral to the test ear. In clinical otoacoustic emission testing carried out in a sound attenuating booth, ambient noise levels are low such that the efferent system is not activated. However in newborn hearing screening, OAEs are often recorded in hospital or clinic environments, where ambient noise levels can be 60-70 dB SPL. Thus, results in the test ear can be influenced by ambient noise stimulating the opposite ear. Surprisingly, in hearing screening protocols there are no recommendations for avoiding contralateral suppression, that is, protecting the opposite ear from noise by blocking the ear canal. In the present study we have compared transient evoked and distortion product OAEs measured with and without contralateral ear plugging, in environmental settings with ambient noise levels $<25 \mathrm{~dB}$ SPL, $45 \mathrm{~dB}$ SPL, and $55 \mathrm{~dB}$ SPL. We found out that without contralateral ear occlusion, ambient noise levels above $55 \mathrm{~dB}$ SPL can significantly attenuate OAE signals. We strongly suggest contralateral ear occlusion in OAE based hearing screening in noisy environments.
\end{abstract}

\section{Introduction}

Audiometric testing in general is best carried out in a low noise environment. Indeed most clinical testing is done in sound attenuating booths, where background noise levels are typically below $20 \mathrm{~dB}$ SPL (for frequencies of audiometric interest). For performing behavioral (pure tone and speech audiometry) and physiological tests (auditory evoked potentials and OAEs) the focus has been on maintaining a good signal to noise ratio for the test signals presented. The issue addressed in the present study pertains not to the test ear but to the contralateral ear that may or may not be occluded. In neonatal or newborn hearing screening with OAEs most protocols do not specify any occlusion or plugging of the nontest ear (e.g., [1-11]). However, such screening tests are routinely carried out in a noisy hospital or clinic environments. Newborn babies may be screened in patient's rooms, clinical areas, or a neonatal intensive care unit (NICU), where ambient sound levels can be as high as $60-70 \mathrm{~dB}$ SPL (e.g., [12-16]). The American Academy of Pediatrics recommends that sound levels in an NICU should not exceed $45 \mathrm{~dB}$, but most often this is not the case. Indeed a review by Konkani and Oakley reveals that ambient noise levels in typical NICUs can exceed $80 \mathrm{~dB}$ SPL [16].

It is now well established that OAEs-discovered by Kemp in 1978 [17] - are suppressed or modulated by acoustic signals presented to the contralateral ear. The role of the olivocochlear neural efferent system in inhibiting outer hair cell activity is well understood [18-24]. The consequent modulation of the outer hair cell mechanics and their contribution to $\mathrm{OAE}$ generation are the basis of clinical tests of the contralateral OAE suppression reflex [25-36].

The question posed in the present study is do ambient noise levels, typical of OAE screening environments, suppress OAEs in the test ear by stimulation of the contralateral, nonoccluded ear? In a sense the answer is already known 


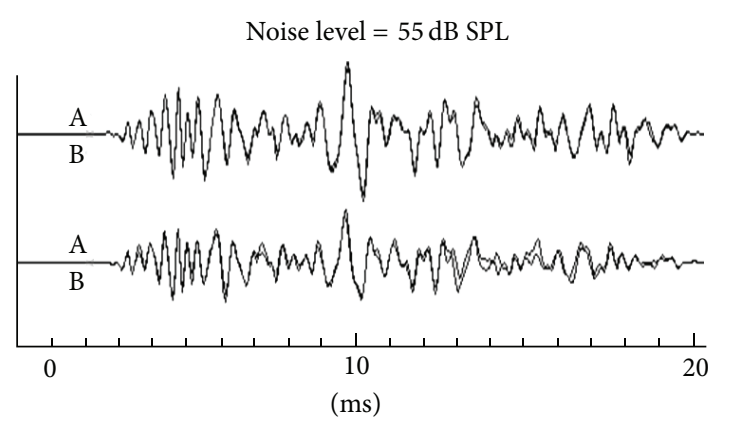

Left ear test, right ear plugged Response $=13.4 \mathrm{~dB}$

Left ear test, right ear unplugged

Response $=11.3 \mathrm{~dB}$

(a)

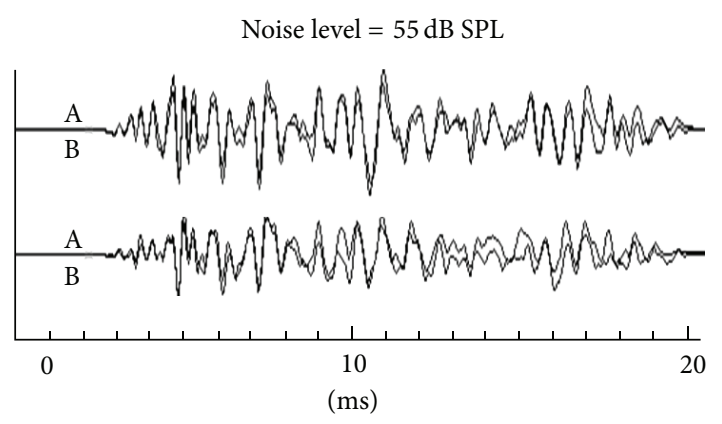

Right ear test, left ear plugged Response $=15.1 \mathrm{~dB}$

Right ear test, left ear unplugged

Response $=13.4 \mathrm{~dB}$

(b)

Noise level $<25 \mathrm{~dB}$ SPL

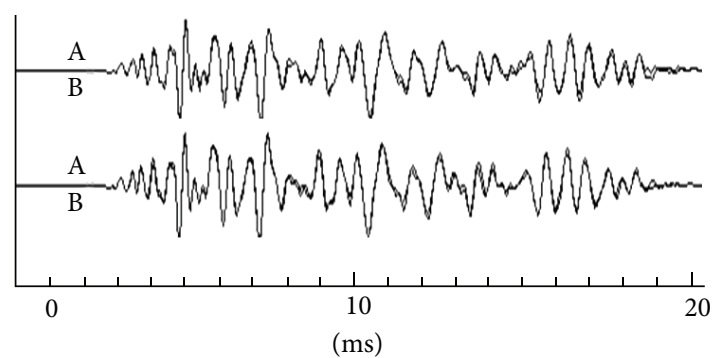

Right ear test, left ear plugged

Response $=14.1 \mathrm{~dB}$

Right ear test, left ear unplugged

Response $=14.2 \mathrm{~dB}$

(c)

FIgURE 1: Differences in TEOAE wave forms (ILO88 format) measured with contralateral ear canal plugged or open, in $55 \mathrm{~dB}$ SPL ambient noise level ((a) and (b)) versus noise levels $<25 \mathrm{~dB}$ SPL (c). Data shown are from one subject.

in that numerous studies (as referenced above) have utilized contralateral sound stimuli to enable OAE suppression, which have stimulus levels that are similar to those of ambient noise. Furthermore, work including that by our own group [35] has clearly shown that OAE suppression is not a reflex with a defined threshold response. The efferent system enables OAE suppression with contralateral stimuli over a wide range of stimulus intensities. In other words acoustic signal levels constantly influence the system. We have chosen to "model" the situation of hearing screening testing in environments with different level of ambient noise.

\section{Materials and Methods}

2.1. Subjects and OAE Measurements. We tested 6 young adult females (18-24 yrs.) with normal audiograms and robust OAEs (signals above noise, in the normal range and repeatable). OAE recordings were made in each individual ear $(N=12)$. Two OAE measurement methods were used. Transient evoked (TE) OAEs (ILO88 Otodynamics, Hatfield, UK) and distortion product (DP) OAEs (Vivo 600DPR; Vivosonic, Toronto, Canada). In each of the 4 acoustic environments (described below) TEOAE and DPOAE measures were repeated 3 times with and without occlusion of the contralateral ear. The ear canal was occluded with a standard memory foam earplug, and a circumaural headphone shell was also worn to achieve a combined attenuation greater than $40 \mathrm{~dB}$. We measured TEOAEs to click stimuli (ILO88 default mode) and quantified using the average $\mathrm{dB}$ response. DPOAEs were measured in the form of a DPgram; $2 f 1-f 2$ signal levels as a function of $f 2$ frequency $(0.25-6 \mathrm{kHz}$; e.g., Figure 3). These DPgrams were quantified by simple average of emission levels at all test frequencies. 
TABLE 1: TEOAE data from six subjects comparing OAE levels with contralateral ear occluded versus open. $P$ values of paired Student's $t$-test results and significance are indicated.

\begin{tabular}{|c|c|c|c|c|c|}
\hline Subject & TEOAE $(\mathrm{dB})$ contra ear plugged & TEOAE (dB) contra ear open & Difference $(\mathrm{dB})$ & $P$ value & Significance \\
\hline \multicolumn{6}{|c|}{ Noise level $<25 \mathrm{~dB}$ SPL } \\
\hline PAP & 14.21 & 14.11 & 0.1 & 0.42 & NO \\
\hline ALL & 9.42 & 9.3 & 0.12 & 0.629 & $\mathrm{NO}$ \\
\hline GLU & 13.1 & 13.4 & -0.3 & 0.471 & NO \\
\hline LAR & 10.35 & 10.05 & 0.3 & 0.46 & $\mathrm{NO}$ \\
\hline HAR & 5.08 & 4.86 & 0.21 & 0.15 & NO \\
\hline SKL & 13.2 & 13.18 & 0.016 & 0.6109 & NO \\
\hline \multicolumn{6}{|c|}{ Noise level c. $45 \mathrm{~dB}$ SPL } \\
\hline PAP & 14.59 & 13.62 & 0.96 & 0.003 & YES \\
\hline ALL & 9.6 & 8.35 & 1.25 & 0.044 & YES \\
\hline GLU & 13.22 & 12.28 & 0.93 & 0.112 & NO \\
\hline LAR & 9.12 & 8.72 & 0.4 & 0.093 & $\mathrm{NO}$ \\
\hline HAR & 5.75 & 5.6 & 0.13 & 0.604 & NO \\
\hline SKL & 12.12 & 11.65 & 0.46 & 0.0004 & YES \\
\hline \multicolumn{6}{|c|}{ Noise level 55 dB SPL } \\
\hline PAP & 13.98 & 12.88 & 1.1 & $<0.0001$ & YES \\
\hline ALL & 8.55 & 7.7 & 1.05 & 0.0085 & YES \\
\hline GLU & 13.55 & 11.9 & 1.65 & $<0.0001$ & YES \\
\hline LAR & 8.78 & 7.9 & 0.88 & 0.151 & NO \\
\hline HAR & 5.75 & 5.0 & 0.21 & 0.021 & YES \\
\hline SKL & 12.28 & 11.92 & 0.366 & 0.0197 & YES \\
\hline \multicolumn{6}{|c|}{ Babble level 55 dB SPL } \\
\hline PAP & 13.63 & 12.62 & 1.02 & 0.0113 & YES \\
\hline ALL & 9.47 & 8.41 & 1.057 & 0.0036 & YES \\
\hline GLU & 13.55 & 12.15 & 1.4 & 0.0002 & YES \\
\hline LAR & 9.43 & 8.33 & 1.1 & 0.009 & YES \\
\hline HAR & 5.95 & 5.38 & 0.56 & 0.035 & YES \\
\hline SKL & 13.35 & 12.95 & 0.4 & 0.0015 & YES \\
\hline
\end{tabular}

2.2. Acoustic Environments. (i) Control experiments were carried out in a sound attenuated booth (single wall ACO) with ambient sound levels below $25 \mathrm{~dB}$ SPL $(100 \mathrm{~Hz}-16 \mathrm{kHz})$. (ii) Experiments were also made in the open laboratory environment, where ambient noise level was approximately $45 \mathrm{~dB}$ SPL. (iii) A study was made in noise-augmented environment in which white noise generation was adjusted to give an overall ambient noise level of $55 \mathrm{~dB}$ SPL. (iv) A recorded babble/shopping mall sound sample was used to provide a $55 \mathrm{~dB}$ SPL ambient noise that was more dynamic in character than the white noise augmented environment. In other words this background noise had significant temporal and spectral fluctuations. All acoustic signal levels were measured in free field at the level of the subject's head using a calibrated (B\&K 4230, $94 \mathrm{~dB} 1 \mathrm{kHz}$ ) sound meter (Larson Davis 831) with halfinch condenser microphone (PCB Piezotronics). We used a linear (nonweighted) mode with a $100 \mathrm{~Hz}-16 \mathrm{kHz}$ bandwidth.

2.3. Data Analysis. For each acoustic condition, TEOAE and DPOAE signals with and without plugging of contralateral ear are compared with a two tailed, paired Student's $t$ test, after confirmation of normal data distribution with Kolmogorov and Smirnov analysis.

\section{Results}

3.1. TEOAE Results. Figure 1 illustrates OAE waveforms evoked by broadband click stimuli in the ILO88 (Otodynamics) format; results are from one subject. Each data pair is a record made with and without contralateral ear plugging. The upper two data records were made in the environment with a $55 \mathrm{~dB}$ SPL ambient noise level. Note the attenuation of the wave forms in the nonplugged ear canal condition. In both cases the TEOAE response is decreased by almost $2 \mathrm{~dB}$. The lower traces show control records in the sound booth; contralateral ear occlusion does not alter TEOAE response.

Table 1 lists, for all 6 subjects, the TEOAE levels (average of 3 repeat recordings) for the contralateral ear plugged and nonplugged conditions. The upper panel shows records made in the sound booth with ambient noise levels $<25 \mathrm{~dB}$ SPL. 
TEOAE with contralateral ear plugged versus open
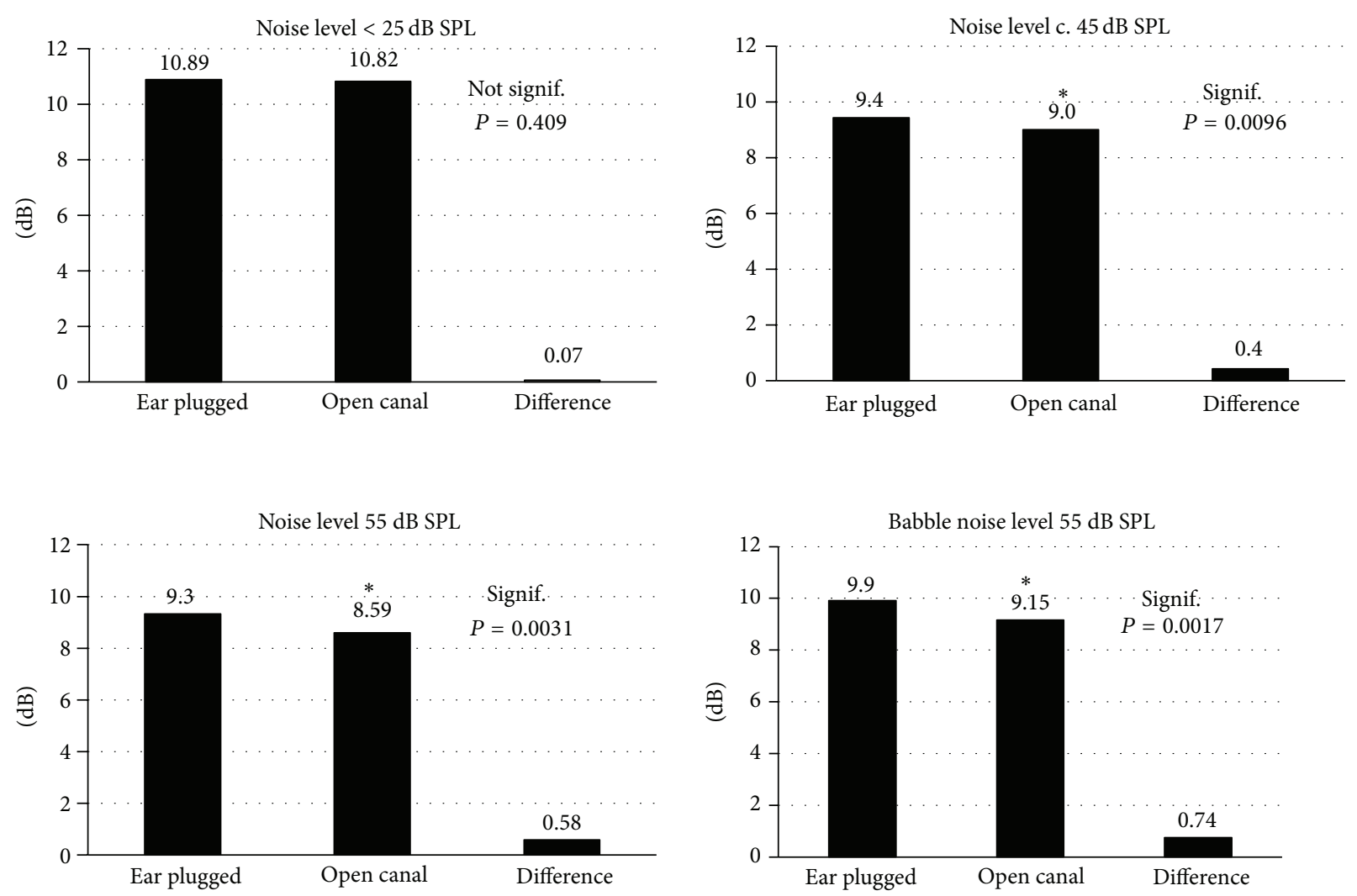

Figure 2: Plots of average DPOAE levels and the difference recoded with contralateral ear occluded or open ( $N=6$ subjects). Significance of the difference (paired Student's $t$-test) is indicated.

There are no significant differences between contralateral ear plugged versus open ear canal conditions. Significance and $P$ values of paired $t$-test results are listed. The lower panels show comparisons in sound environments with noise levels at $45 \mathrm{~dB}$ SPL and in (white) noise and babble noise augmented environments ( $55 \mathrm{~dB} \mathrm{SPL}$ ). In the $45 \mathrm{~dB}$ SPL environment three subjects have statistically significant differences in OAE level with versus without opposite ear plugging. In the $55 \mathrm{~dB}$ SPL ambient noise environments all but one subject show significant differences between TEOAE levels with and without opposite ear occlusion. Figure 2 shows pooled subject data for each sound environment. Overall there is a significant difference in TEOAE levels for environments with ambient noise levels of $45 \mathrm{~dB}$ and above.

3.2. DPOAE Results. Figure 3 shows DPgrams for two subjects measured in an environment with ambient noise at $55 \mathrm{~dB}$ SPL. In each case the solid lines indicate DPOAE level measured with contralateral ears plugged versus unplugged (dashed lines). Note the suppression caused by the environmental noise, especially between 0.5 and $1 \mathrm{kHz}$, where the decrease in DPOAE level amounted up to $3 \mathrm{~dB}$. Table 2 shows data from all 6 subjects. The $55 \mathrm{~dB}$ ambient environmental noise results in a significant contralateral suppression in only some subjects. However, it will be noted that the subjects with a significant suppression effect are those with an initially higher level DPOAE (subject list in Table 2 is ordered according to DPOAE level). Furthermore, the $P$ values for the paired $t$-test are mainly low hinting of an effect. Indeed an analysis of pooled results graphed in Figure 4 shows a very significant effect $(P<0.0001)$ of the $55 \mathrm{~dB}$ SPL environmental noise.

\section{Discussion}

There has been some considerable attention paid to the issue of ambient noise in environments in which OAE screening tests are carried out. The main concerns however have related to the test ear rather than the contralateral ear. Thus there is concern about the signal-to-noise ratio in the test ear that has to be high for getting a valid OAE response [37, 38]. The authors are unaware of studies that have considered the effects of ambient noise on the contralateral ear. As previously mentioned, there are no provisions or recommendations to use occlusion of the contra lateral ears in screening testing, and thus the contralateral suppression effects on test ear OAEs is an issue. The effects of contralateral acoustic stimulation on OAEs have been extensively documented in experimental studies, animal models, and clinical research. It is surprising therefore that these effects have not been seriously considered in newborn hearing screening protocols that employ OAE measures. 
Average DPOAE grams with and without plugging of contralateral ear

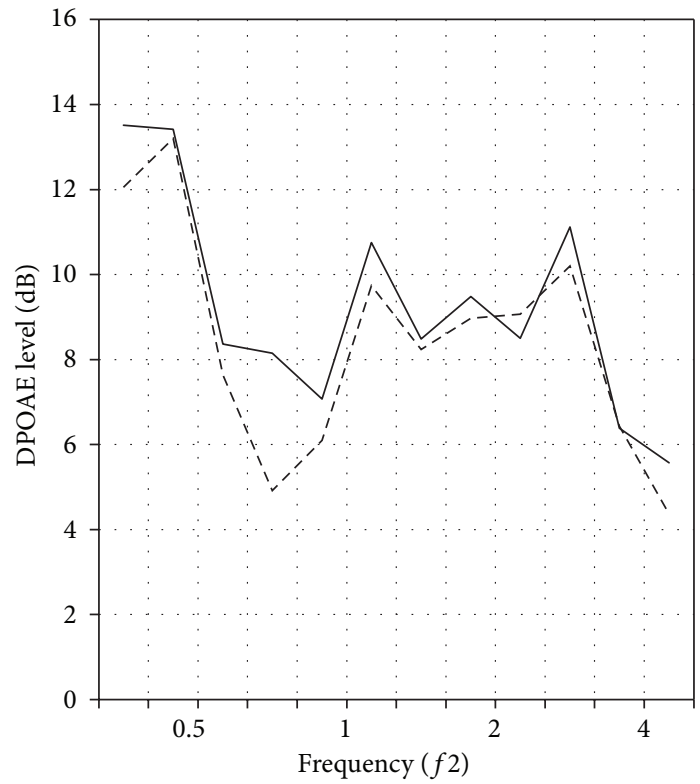

Subject PAP: DPOAE averages $(n=3)$ for contralateral ear plugged (continuous line), contralateral ear canal open (dashed line) Ambient noise level c. $55 \mathrm{~dB}$ SPL

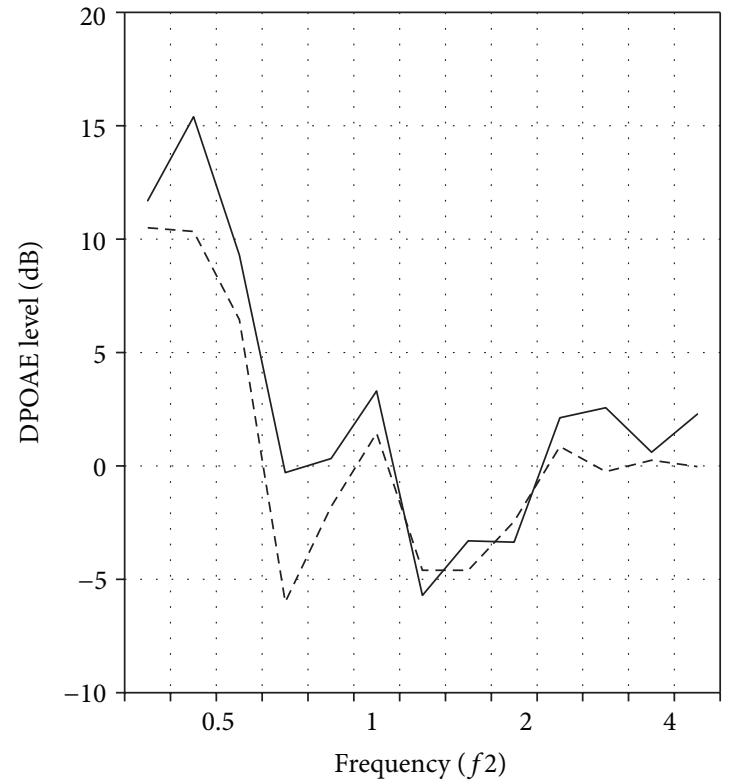

Subject HAR: DPOAE averages $(n=3)$ for contralateral ear plugged (continuous line), contralateral ear canal open (dashed line) Ambient babble noise level c. $55 \mathrm{~dB}$ SPL

Figure 3: Example DPOAE (2f1- $f 2)$ versus frequency $(f 2)$ plots, DPgrams, for two subjects measured with (solid lines) and without (dashed curves) contralateral ear canal occlusion. Measurements were made in an environment with an ambient noise level of $55 \mathrm{~dB}$ SPL. DP grams shown are an average of three sequential recordings.

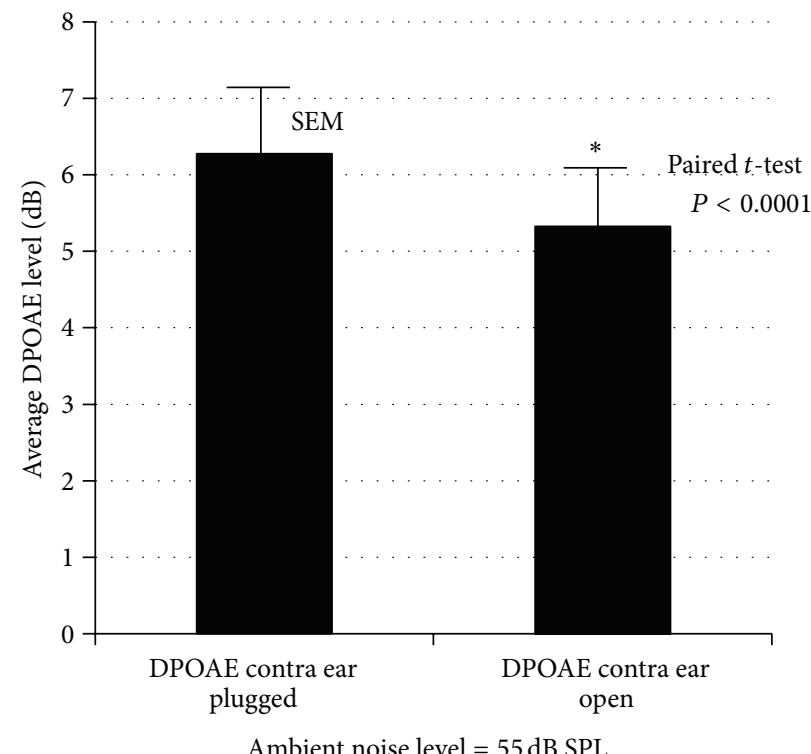

FIGURE 4: Average DPOAE level changes between contralateral ear open versus occluded conditions, measured in an environment with an ambient noise level of $55 \mathrm{~dB}$ SPL. Significant difference as indicated by paired Student's $t$-test. 
TABLE 2: DPOAE data from six subjects indicating OAE level recorded with and without occlusion of the contralateral ear in four different ambient sound environments. Results of Student's $t$-test are indicated.

\begin{tabular}{|c|c|c|c|c|c|}
\hline Subject & DPOAE $(\mathrm{dB})$ contra ear plugged & DPOAE $(\mathrm{dB})$ contra ear open & Difference & $P$ value & Significance \\
\hline \multicolumn{6}{|c|}{ Noise level $<25 \mathrm{~dB}$ SPL } \\
\hline PAP & 10.76 & 10.77 & -0.014 & 0.937 & $\mathrm{NO}$ \\
\hline DAV & 9.73 & 9.66 & 0.07 & 0.88 & NO \\
\hline LAR & 6.9 & 6.59 & 0.3 & 0.378 & NO \\
\hline ALL & 4.38 & 4.3 & 0.087 & 0.625 & NO \\
\hline HAR & 3.94 & 3.62 & 0.32 & 0.234 & NO \\
\hline GLU & 2.8 & 1.64 & 1.165 & 0.105 & $\mathrm{NO}$ \\
\hline \multicolumn{6}{|c|}{ Noise level c. 45 dB SPL } \\
\hline DAV & 12.56 & 12.39 & 0.168 & 0.457 & NO \\
\hline PAP & 8.78 & 8.56 & 0.23 & 0.467 & $\mathrm{NO}$ \\
\hline LAR & 6.9 & 6.37 & 0.53 & 0.351 & NO \\
\hline HAR & 5.48 & 4.97 & 0.51 & 0.66 & $\mathrm{NO}$ \\
\hline ALL & 5.21 & 4.58 & 0.63 & 0.323 & NO \\
\hline GLU & 2.32 & 2.18 & 0.148 & 0.805 & $\mathrm{NO}$ \\
\hline \multicolumn{6}{|c|}{ Noise level 55 dB SPL } \\
\hline DAV & 10.96 & 10.22 & 0.74 & 0.0861 & almost \\
\hline PAP & 8.73 & 7.95 & 0.777 & 0.0995 & almost \\
\hline LAR & 7.5 & 6.02 & 1.48 & 0.001 & YES \\
\hline HAR & 5.68 & 4.37 & 1.31 & 0.153 & NO \\
\hline ALL & 4.14 & 3.21 & 0.92 & 0.117 & NO \\
\hline GLU & 3.23 & 2.39 & 0.84 & 0.2537 & NO \\
\hline \multicolumn{6}{|c|}{ Babble level $55 \mathrm{~dB}$ SPL } \\
\hline PAP & 10.12 & 9.13 & 0.99 & 0.0061 & YES \\
\hline LAR & 7.27 & 5.7 & 1.56 & 0.0481 & YES \\
\hline DAV & 6.96 & 5.5 & 1.46 & 0.0054 & YES \\
\hline HAR & 4.49 & 4.03 & 0.45 & 0.417 & $\mathrm{NO}$ \\
\hline ALL & 4.62 & 3.39 & 1.23 & 0.165 & NO \\
\hline GLU & 1.62 & 1.96 & -0.34 & 0.627 & $\mathrm{NO}$ \\
\hline
\end{tabular}

In the present study, we have tested the hypothesis that moderate levels of environmental noise can suppress OAE responses by activation of the olivocochlear efferent system. In the present study a level of $55 \mathrm{~dB}$ SPL has a significant effect. Given that most hospital ward and clinic environments have ambient noise levels higher than $55 \mathrm{~dB}$ SPL we conclude that, unless the untested ear is occluded, there will almost certainly be a suppression effect. It should be noted that clinical diagnostic OAE testing is almost always carried out in a low noise environment, typically in a sound attenuating booth. Here the problem of contralateral ear stimulation is negligible. However, in neonatal hearing OAE screening the availability of a sound booth or even a quiet environment is not a reality. It has been suggested that the olivocochlear efferent system is not fully matured or operational in a neonatal human subject, and therefore the precaution of occluding the contralateral ear is unnecessary. It has been reported that in some species efferent innervation is one of the final stages of cochlear maturation [39-41]. In the mouse, an altricious species, efferents do not fully connect with outer hair cells until postnatal day 20 [42]. However, the human is a precocious species with a much more mature peripheral auditory system at birth. There is some evidence that continued maturation of contralateral OAE suppression continues for some weeks after term birth [43]. However, a number of authors report that OAE suppression reflexes can be recorded in at term $[36,44,45]$.

The results of this present study indicate that with a $55 \mathrm{~dB}$ ambient noise OAE levels can be attenuated by as much as $3 \mathrm{~dB}$. It could be argued that such small attenuations will be of little significance in a screening test. However, it should be noted that this level of ambient noise is very low compared with that in a typical NICU or hospital clinic environment. Furthermore, $3 \mathrm{~dB}$ is a significant level change when the original OAE signal level may be of a similar order of magnitude. Will small OAE attenuations make a difference in a pass/refer (fail) screening paradigm? We suggest that it will definitely lead to more false positive results, and that means increasing parent anxiety and further healthcare costs.

\section{Conclusion}

In OAE screening tests, a nonoccluded contralateral ear will be stimulated by ambient environmental noise. Noise levels 
above $55 \mathrm{~dB}$ SPL can significantly suppress OAEs in the test ear and lead to false positive results. Such inaccuracy can be avoided by occlusion of the contralateral ear canal.

\section{Conflict of Interests}

The authors declare that there is no conflict of interests regarding the publication of this paper.

\section{Acknowledgment}

The Canadian Institutes of Health Research (CIHR) funded this study.

\section{References}

[1] American Academy of Pediatrics, Joint Committee on Infant Hearing, "Year 2007 position statement: principles and guidelines for early hearing detection and intervention programs," Pediatrics, vol. 120, no. 4, pp. 898-921, 2007.

[2] H. D. Nelson, C. Bougatsos, and P. Nygren, "Universal newborn hearing screening: systematic review to update the 2001 US preventive services task force recommendation," Pediatrics, vol. 122, no. 1, pp. e266-e276, 2008.

[3] W. D. Eiserman, D. M. Hartel, L. Shisler, J. Buhrmann, K. R. White, and T. Foust, "Using otoacoustic emissions to screen for hearing loss in early childhood care settings," International Journal of Pediatric Otorhinolaryngology, vol. 72, no. 4, pp. 475482, 2008.

[4] T. Foust, W. Eiserman, L. Shisler, and A. Geroso, "Using otoacoustic emissions to screen young children for hearing loss in primary care settings," Pediatrics, vol. 132, no. 1, pp. 118-123, 2013.

[5] M. J. Barker, E. K. Hughes, and M. Wake, "NICU-only versus universal screening for newborn hearing loss: population audit," Journal of Paediatrics and Child Health, vol. 49, no. 1, pp. E74E79, 2013.

[6] V. S. de Freitas, K. de Freitas Alvarenga, M. C. Bevilacqua, M. A. N. Martinez, and O. A. Costa, "Critical analysis of three newborn hearing screening protocols," Pro-Fono, vol. 21, no. 3, pp. 201-206, 2009.

[7] S. Hatzopoulos, J. Petruccelli, A. Ciorba, and A. Martini, “Optimizing otoacoustic emission protocols for a UNHS program," Audiology and Neurotology, vol. 14, no. 1, pp. 7-16, 2008.

[8] M. Ptok, "Fundamentals of hearing screening in neonates (standard of care)," Zeitschrift fur Geburtshilfe und Neonatologie, vol. 207, no. 5, pp. 194-196, 2003.

[9] S. Bansal, A. Gupta, and A. Nagarkar, "Transient evoked otoacoustic emissions in hearing screening programs-Protocol for developing countries," International Journal of Pediatric Otorhinolaryngology, vol. 72, no. 7, pp. 1059-1063, 2008.

[10] G. Pastorino, P. Sergi, M. Mastrangelo et al., "The Milan Project: a newborn hearing screening programme," Acta Paediatrica, vol. 94, no. 4, pp. 458-463, 2005.

[11] D. J. MacKenzie and L. G. U. Galbrun, "Noise levels and noise sources in acute care hospital wards," Building Services Engineering Research and Technology, vol. 28, no. 2, pp. 117-131, 2007.

[12] E. McLaren and C. Maxwell-Armstrong, "Noise pollution on an acute surgical ward," Annals of the Royal College of Surgeons of England, vol. 90, no. 2, pp. 136-139, 2008.
[13] W. B. Carvalho, M. L. G. Pedreira, and M. A. L. De Aguiar, "Noise level in a pediatric intensive care unit," Jornal de Pediatria, vol. 81, no. 6, pp. 495-498, 2005.

[14] J. L. Darbyshire and J. D. Young, "An investigation of sound levels on intensive care units with reference to the WHO guidelines," Critical Care, vol. 17, no. 5, p. R187, 2013.

[15] C. Tegnestedt, A. Günther, A. Reichard et al., "Levels and sources of sound in the intensive care unit-an observational study of three room types," Acta Anaesthesiologica Scandinavica, vol. 57, no. 8, pp. 1041-1050, 2013.

[16] A. Konkani and B. Oakley, "Noise in hospital intensive care units-a critical review of a critical topic," Journal of Critical Care, vol. 27, no. 5, pp. 522.e1-522.e9, 2012.

[17] D. T. Kemp, "Stimulated acoustic emissions from within the human auditory system," Journal of the Acoustical Society of America, vol. 64, no. 5, pp. 1386-1391, 1978.

[18] J. H. Siegel and D. O. Kim, "Effect neural control of cochlear mechanics? Olivocochlear bundle stimulation affects cochlear biomechanical nonlinearity," Hearing Research, vol. 6, no. 2, pp. 171-182, 1982.

[19] M. C. Liberman, "Rapid assessment of sound-evoked olivocochlear feedback: suppression of compound action potentials by contralateral sound," Hearing Research, vol. 38, no. 1-2, pp. 47-56, 1989.

[20] E. H. Warren III and M. C. Liberman, "Effects of contralateral sound on auditory-nerve responses. I. Contributions of cochlear efferents," Hearing Research, vol. 37, no. 2, pp. 89-104, 1989.

[21] M. C. Liberman, S. Puria, and J. J. Guinan Jr., "The ipsilaterally evoked olivocochlear reflex causes rapid adaptation of the 2f1-f2 distortion product otoacoustic emission," Journal of the Acoustical Society of America, vol. 99, no. 6, pp. 3572-3584, 1996.

[22] J. J. Guinan Jr., "Olivocochlear efferents: anatomy, physiology, function, and the measurement of efferent effects in humans," Ear and Hearing, vol. 27, no. 6, pp. 589-607, 2006.

[23] A. L. James, R. V. Harrison, M. Pienkowski, H. R. Dajani, and R. J. Mount, "Dynamics of real time DPOAE contralateral suppression in chinchillas and humans," International Journal of Audiology, vol. 44, no. 2, pp. 118-129, 2005.

[24] J. B. Mott, S. J. Norton, S. T. Neely, and W. B. Warr, "Changes in spontaneous otoacoustic emissions produced by acoustic stimulation of the contralateral ear," Hearing Research, vol. 38, no. 3, pp. 229-242, 1989.

[25] L. Collet, D. T. Kemp, E. Veuillet, R. Duclaux, A. Moulin, and A. Morgon, "Effect of contralateral auditory stimuli on active cochlear micro-mechanical properties in human subjects," Hearing Research, vol. 43, no. 2-3, pp. 251-261, 1990.

[26] J.-L. Puel and G. Rebillard, "Effect of contralateral sound stimulation on the distortion product 2F1-F2: evidence that the medial efferent system is involved," Journal of the Acoustical Society of America, vol. 87, no. 4, pp. 1630-1635, 1990.

[27] E. Veuillet, L. Collet, and R. Duclaux, "Effect of contralateral acoustic stimulation on active cochlear micromechanical properties in human subjects: dependence on stimulus variables," Journal of Neurophysiology, vol. 65, no. 3, pp. 724-735, 1991.

[28] A. Moulin, L. Collet, and R. Duclaux, "Contralateral auditory stimulation alters acoustic distortion products in humans," Hearing Research, vol. 65, no. 1-2, pp. 193-210, 1993.

[29] C. I. Berlin, L. J. Hood, A. Hurley, and H. Wen, "Contralateral suppression of otoacoustic emissions: an index of the function of the medial olivocochlear system," Otolaryngology_Head and Neck Surgery, vol. 110, no. 1, pp. 3-21, 1994. 
[30] D. M. Williams and A. M. Brown, "The effect of contralateral broad-band noise on acoustic distortion products from the human ear," Hearing Research, vol. 104, no. 1-2, pp. 127-146, 1997.

[31] A. L. Giraud, J. Wable, A. Chays, L. Collet, and S. ChéryCroze, "Influence of contralateral noise on distortion product latency in humans: is the medial olivocochlear efferent system involved?" Journal of the Acoustical Society of America, vol. 102, no. 4, pp. 2219-2227, 1997.

[32] S. Maison, C. Micheyl, G. Andéol, S. Gallégo, and L. Collet, "Activation of medial olivocochlear efferent system in humans: influence of stimulus bandwidth," Hearing Research, vol. 140, no. 1-2, pp. 111-125, 2000.

[33] A. L. James, R. J. Mount, and R. V. Harrison, "Contralateral suppression of DPOAE measured in real time," Clinical Otolaryngology and Allied Sciences, vol. 27, no. 2, pp. 106-112, 2002.

[34] J. J. Guinan Jr., B. C. Backus, W. Lilaonitkul, and V. Aharonson, "Medial olivocochlear efferent reflex in humans: otoacoustic emission (OAE) measurement issues and the advantages of stimulus frequency OAEs," Journal of the Association for Research in Otolaryngology, vol. 4, no. 4, pp. 521-540, 2003.

[35] R. V. Harrison, A. Sharma, T. Brown, S. Jiwani, and A. L. James, "Amplitude modulation of DPOAEs by acoustic stimulation of the contralateral ear," Acta Oto-Laryngologica, vol. 128, no. 4, pp. 404-407, 2008.

[36] A. L. James, “The assessment of olivocochlear function in neonates with real-time distortion product otoacoustic emissions," Laryngoscope, vol. 121, no. 1, pp. 202-213, 2011.

[37] J. T. Jacobson, "The effects of noise in transient EOAE newborn hearing screening," International Journal of Pediatric Otorhinolaryngology, vol. 29, no. 3, pp. 235-248, 1994.

[38] B. O. Olusanya, "Ambient noise levels and infant hearing screening programs in developing countries: an observational report," International Journal of Audiology, vol. 49, no. 8, pp. 535-541, 2010.

[39] A. Shnerson, C. Devigne, and R. Pujol, "Age-related changes in the C57BL/6J mouse cochlea. II. Ultrastructural findings," Brain Research, vol. 254, no. 1, pp. 77-88, 1981.

[40] D. D. Simmons, "Development of the inner ear efferent system across vertebrate species," Journal of Neurobiology, vol. 53, no. 2, pp. 228-250, 2002.

[41] A. V. Bulankina and T. Moser, "Neural circuit development in the mammalian cochlea," Physiology, vol. 27, no. 2, pp. 100-112, 2012.

[42] Y. Narui, A. Minekawa, T. Iizuka et al., "Development of distortion product otoacoustic emissions in C57BL/6J mice," International Journal of Audiology, vol. 48, no. 8, pp. 576-581, 2009.

[43] R. Chabert, M. J. Guitton, D. Amram et al., "Early maturation of evoked otoacoustic emissions and medial olivocochlear reflex in preterm neonates," Pediatric Research, vol. 59, no. 2, pp. 305308, 2006.

[44] C. Abdala, E. Ma, and Y. S. Sininger, "Maturation of medial efferent system function in humans," Journal of the Acoustical Society of America, vol. 105, no. 4, pp. 2392-2402, 1999.

[45] T. Morlet, A. Hamburger, J. Kuint et al., "Assessment of medial olivocochlear system function in pre-term and full-term newborns using a rapid test of transient otoacoustic emissions," Clinical Otolaryngology and Allied Sciences, vol. 29, no. 2, pp. 183-190, 2004. 


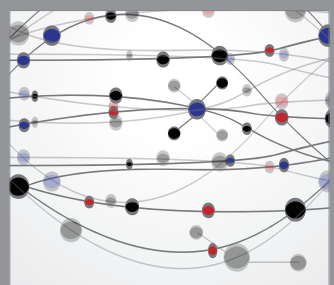

The Scientific World Journal
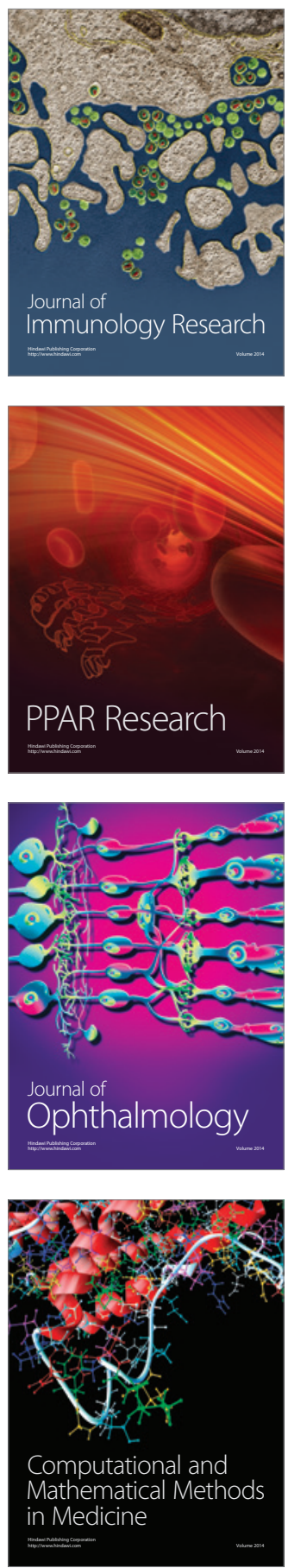

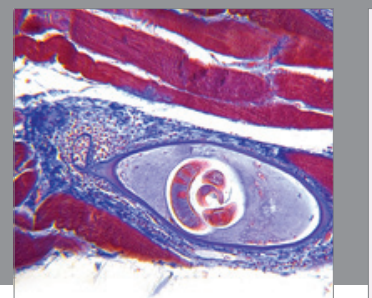

Gastroenterology

Research and Practice
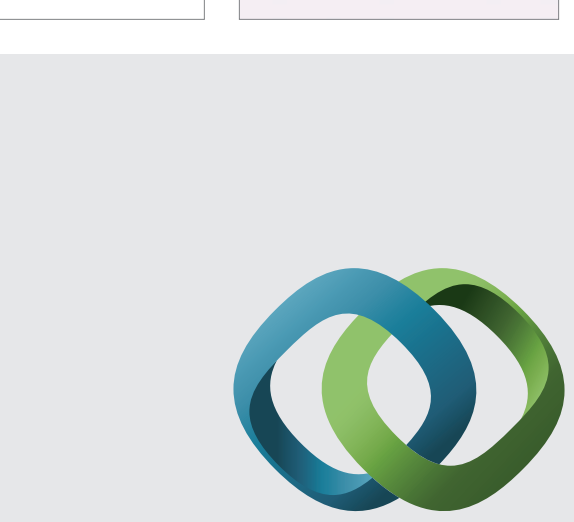

\section{Hindawi}

Submit your manuscripts at

http://www.hindawi.com
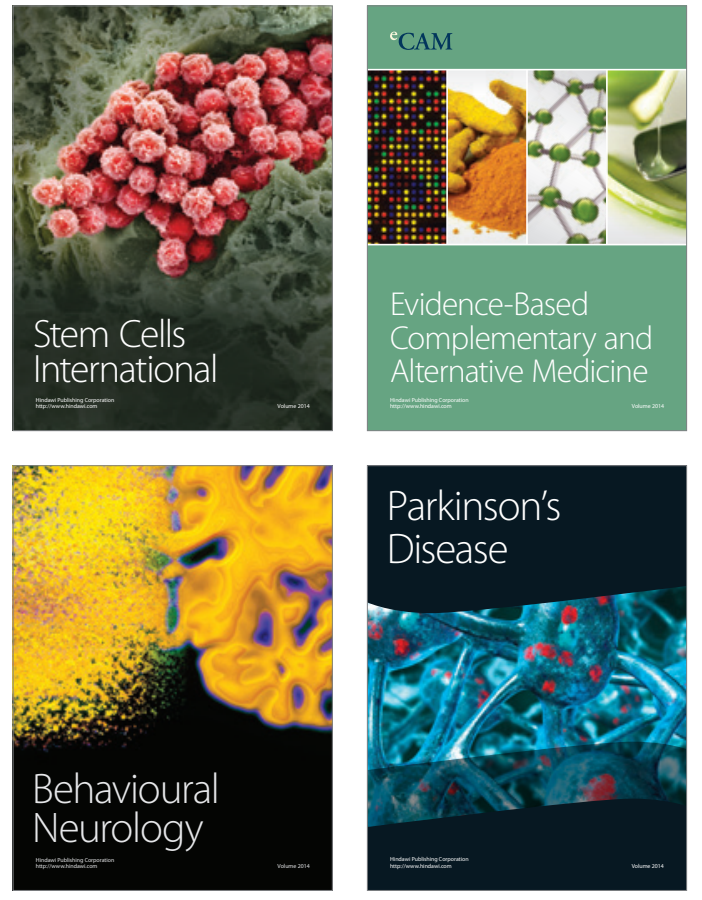
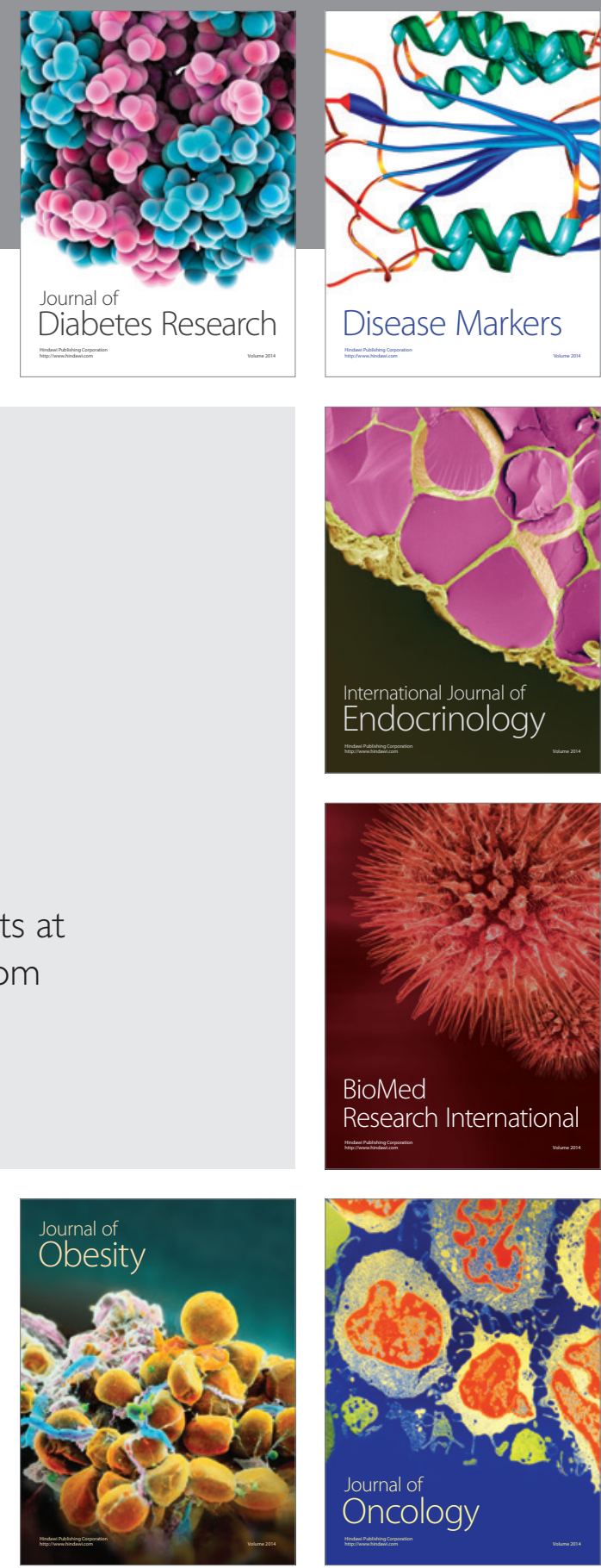

Disease Markers
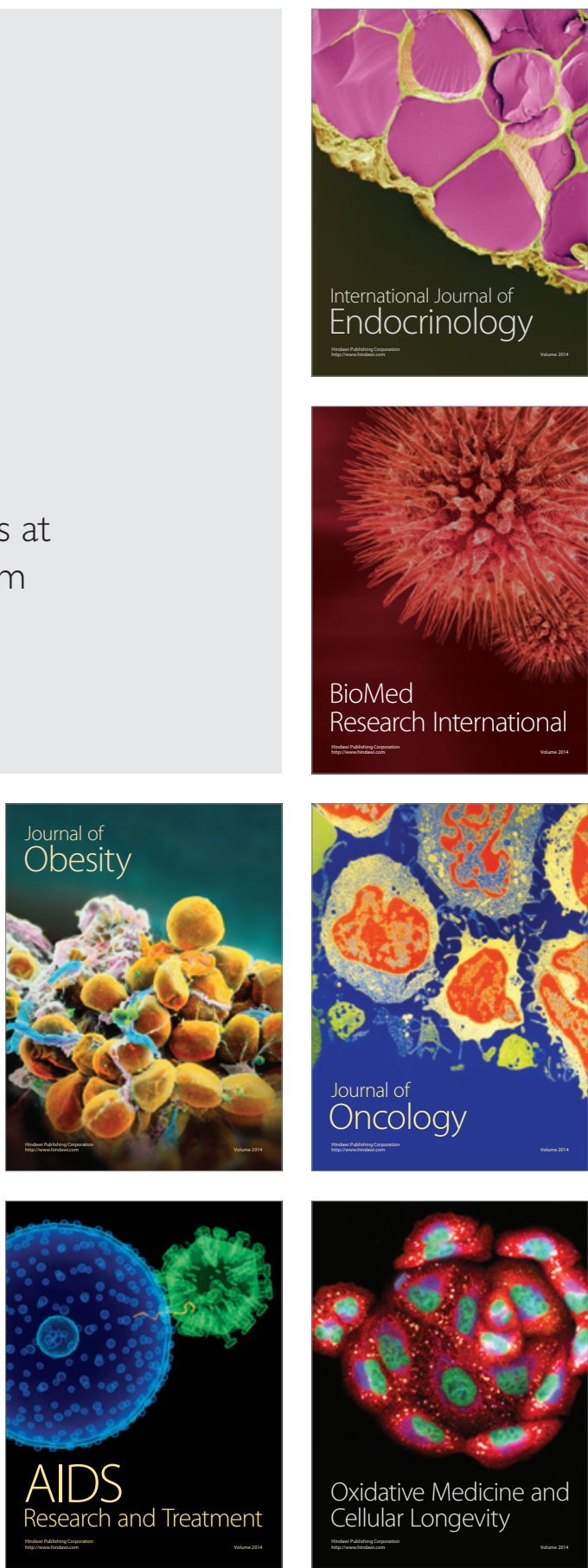